\title{
A Survey of Soldiers' Attitudes to Tattooing
}

\author{
Maj M C Gadd * \\ MRCGP, RAMC
}

The Garrison Medical Centre, Larkhill, Salisbury, Wiltshire

SUMMARY: A study was performed at the Garrison Medical Centre, Larkhill to assess the incidence of skin tattoos info sample of soldiers. The soldiers were questioned with the aim of establishing where they had had their tattoos dono identifying any factors involved in becoming tattooed and assessing what proportion later regretted their actions.

The study included 450 male soldiers. Assessment was by a questionnaire completed in the medical centre waitiog room.

Overall $44 \%$ of the soldiers questioned were tattooed. Most $(85.7 \%)$ had had tattoos done by recognised artists in the United Kingdom. Younger soldiers had a significantly higher incidence of 'home made' tattoos.

Peer pressure was identified as an important influence on the decision to become tattooed. $31.1 \%$ of tattooed soldiegsis regretted their tattoos. This figure rose to $44.6 \%$ in those over 26 years old.

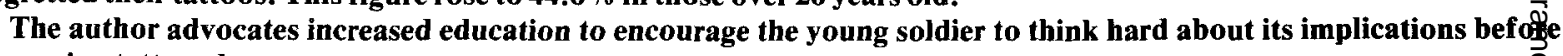
becoming tattooed.

\section{Introduction}

Any health care worker dealing with British soldiers is soon struck by the number and variety of tattoos encountered. The aim of this study was to observe the incidence of skin tattoos in a sample population of soldiers, to assess by whom they were being done and who influenced the soldiers' decision to become tattooed. The study also wished to establish if they later had any regrets about their tattoos and if they would consider removal.

Previous studies $(1,2)$ have suggested an overall incidence of skin tattoos in the male population of about $15 \%$. It has also been suggested (3) that the incidence in soldiers is higher than the general population. This study set out to establish if this were true in a sample population taken from a regular army garrison in the United Kingdom.

The application of tattoos is not without health risks. The potential for transmission of HIV exists (4) and hepatitis infection is well documented (5). The nature of military life may take soldiers overseas where tattooing can expose them to other diseases such as tuberculosis (6) and leprosy (7). The survey wished to establish who was performing tattoos on soldiers. Thus the subjects were questioned as to whether their tattoos were done by someone they considered to be a 'recognised UK tattooist', a tattooist abroad or by themselves or friends.

Previous studies $(1,8)$ have shown strong evidence of the contribution of gang influences on the decision to become tattooed. Work with US soldiers (3) found a higher incidence of tattoos than in the general population and attributed this to the presence of 'marginal community identity' in soldiers. This study attempted to assess the degree of influence from friends and members of the opposite sex on their decision to become tattooed.

The increased interest in new methods of tattoo removal both in the lay and medical press over the last few

years $(9,10,11)$ may prompt men unhappy with theip tattoos to request removal. This study attempted $\mathcal{C O}_{0}$ identify what proportion of soldiers regretted hayigg had their tattoos done and how many would conf̧der removal.

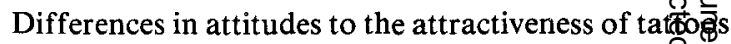
between those in the study who were tattooed and those who were not were also explored. It was also decided te compare the responses of different age groups. Itgras hoped that such information would be of help its the effective targetting of health promotion efforts resar ing tattooing.

\section{Method}

The study was carried out at the Garrison Medic Centre, Larkhill. All soldiers serving in the garrison aæe registered with the practice. The study subjects we male officers and soldiers between the ages of 17 and $\overline{59}$. An initial pilot study was performed to ensure that the time taken to fill in the questionnaire was not excessive and that questions were easily understood. Following this all Regular Army male officers and soldiers atten ing the medical centre during a one month period in May 1990 for any reason, medical, administrative or socia l were requested to complete a questionnaire on their fir visit of the study month. Repeat filling in of questionnaires was prevented by ticking off the subject's nange from a garrison nominal role.

Subjects were given a questionnaire on entering the building and were asked to complete it on their own the waiting room. The practice operates an appointment system so the waiting room was never overcrowdof during the study period. They were instructed to hand the completed form back to the reception staff. This wors then posted into a large box without the staff opening the first (explanatory) page. All answers were anonymous. 
The respondents were asked if they were tattooed. Those responding 'yes' were then questioned on the number they had, if these were done whilst out with male or female friends and where their tattoos were done. They were then asked if they regretted any of their tattoos and if they would consider removal. Further questions were asked on when their last tattoo was done. All responders, irrespective of whether they did or did not have tattoos were questioned on their opinions as to the attractiveness of tattoos to women and the attractiveness of tattoos in women.

All subjects were then asked to give their age on the questionnaire. This would allow comparison between younger and older subjects. It was decided to compare the results obtained for those aged 25 and under with those aged 26 or older.

When associations between aspects of tattooing and other factors were of interest the chi-squared test was used to assess significance.

\section{Results}

Four hundred and fifty potential subjects attended the medical centre during the study period. Of these 445 fully completed a questionnaire. Of the five men not included in the final analysis of results two completed their questionnaires in such a way that they could not be analysed and the remaining three were either themselves seriously ill or accompanying a relative who was.

\section{Table 1}

Numbers (with percentages in brackets) of tattooed soldiers.

\begin{tabular}{lccc} 
& $\begin{array}{c}\text { Age 25 } \\
\text { or under }\end{array}$ & $\begin{array}{c}\text { Age 26 } \\
\text { or older }\end{array}$ & \multicolumn{1}{c}{ Total } \\
\hline Tattooed & $95(46.1)$ & $101(42.3)$ & $196(44.0)$ \\
Not tattooed & $111(53.9)$ & $138(57.7)$ & $249(56.0)$ \\
Totals & $206(46.3)$ & $239(53.7)$ & 445 \\
\hline
\end{tabular}

Chi-squared $=0.52, p=0.5$.

Table 1 shows the number of subjects in the study who admitted to being tattooed. Overall $44 \%$ of the soldiers completing the questionnaire had tattoos. Statistical analysis revealed that there were no significant differences in numbers of tattooed individuals between the two age groups.

Table 2 shows the number of tattooed soldiers responding positively to questioning about where their tattoos were done. As a soldier may have had several tattoos done in several different places these categories are not mutually exclusive. Eighty five point seven percent of tattooed subjects had one or more of their tattoos done by a person who they considered to be a recognised UK tattooist, $36.2 \%$ by a recognised tattooist abroad, $17.9 \%$ had self done tattoos and $15.3 \%$ had tattoos done by friends.

When the younger and older age groups were com-
Table 2

Origin of Tattoos. (Percentages in brackets.)

Age

25 or under 26 or over Total

\begin{tabular}{|c|c|c|c|}
\hline UK Tattooist & $78(82.1)$ & $90(89.1)$ & $168(85.7)$ \\
\hline $\begin{array}{l}\text { Tattooist } \\
\text { Abroad }\end{array}$ & $21(22.1)$ & $50(49.5)$ & $71(36.2)$ \\
\hline $\begin{array}{l}\text { Tattooed by } \\
\text { Self }\end{array}$ & $33(34.7)$ & $2(2.0)$ & $35(17.9)$ \\
\hline $\begin{array}{l}\text { Tattooed by } \\
\text { Friends } \\
\text { Influence } \\
\text { from male }\end{array}$ & $28(29.5)$ & $2(2.0)$ & $30(15.3)$ \\
\hline $\begin{array}{l}\text { friends } \\
\text { Influence }\end{array}$ & $54(56.8)$ & $71(70.3)$ & $125(63.8)$ \\
\hline $\begin{array}{l}\text { from girls } \\
\text { Done as a }\end{array}$ & $17(17.9)$ & $17(16.8)$ & $34(17.3)$ \\
\hline Dare & $32(33.7)$ & $40(39.6)$ & $72(36.7)$ \\
\hline
\end{tabular}

pared it was noted that a higher percentage of the oldefw age group had tattoos done abroad. Of the youngeb subjects $34.7 \%$ admitted to self tattooing and $29.5 \%$ to tattoos done by friends. This compared with a $2 \%$ sele and $2 \%$ friend performed rate in the older age groupi significant difference.

The results of questioning about the influences on subject's decision to become tattooed are given in Ta儒 2 . It is apparent that peer group pressure $(63 \%$ of casest plays a large part in influencing the recipient's decisignce This compared with a figure of $17 \%$ who felt that had influenced their decision to become tattooed.

Results for those tattooed soldiers who expressed? grets at one or more of their tattoos are shown in Table 30 Overall $31.1 \%$ regretted one or more of their tattoos an this feeling was significantly more common amongst the older group. When asked if they would consider remova $\vec{B}$ of any of their tattoos (Table 3) $32.1 \%$ of the subjects

Table 3

Numbers (with percentages in brackets) of tattooe $\bar{\phi}$ soldiers expressing regrets or considering removal.

\begin{tabular}{lccc} 
& $\begin{array}{c}\text { Age 25 } \\
\text { or under }\end{array}$ & $\begin{array}{c}\text { Age 26 } \\
\text { or older }\end{array}$ & \multicolumn{1}{c}{ Total } \\
\hline Regrets & $16(16.8)$ & $45(44.6)$ & $61(31.1)$ \\
No Regrets & $79(83.2)$ & $56(55.4)$ & $135(68.9)$ \\
Total & $95(48.5)$ & $101(51.5)$ & 196
\end{tabular}

Chi-squared $=16.27, \mathrm{p}<0.0001$.

Removal

Considered 18(18.9) 45(44.6)

Removal Not

Considered

$77(81.1)$

Totals

95(48.5)

$101(51.5)$

196

63(32.1)

133(67.9)

Chi-squared $=13.57, \mathrm{p}=0.0002$.

(4)


Table 4

Relationships (with percentages in brackets) between number of tattoos/years since last tattoo and regrets.

\begin{tabular}{|c|c|c|c|}
\hline & Regrets & No Regrets & Total \\
\hline $\begin{array}{l}6 \text { or more } \\
\text { tattoos } \\
5 \text { or less }\end{array}$ & $16(33.3)$ & $32(66.6)$ & $48(24.5)$ \\
\hline tattoos & $45(30.4)$ & $103(69.6)$ & $148(75.5)$ \\
\hline $\begin{array}{l}6 \text { or more years } \\
\text { since last tattoo } \\
5 \text { or less years } \\
\text { since last tattoo }\end{array}$ & $38(44.7)$ & $47(55.3)$ & $85(43.4)$ \\
\hline
\end{tabular}

Relationship with 'number of tattoos': chisquared $=0.04, p=0.8$.

Relationship with 'years since last tattoo': chisquared $=11.82, \mathrm{p}=0.0001$.

felt that they would, with a significantly higher number of the older age group responding positively.

The relationship between the number of tattoos which an individual had and any feelings of regret were evaluated. A comparison between the number of years since a man's last tattoo and any expression of regret was also made. The results (Table 4) show that there was little difference in the percentage regretting their tattoos between those with six or more and those with five or less. However, significantly more men did have regrets when their tattoos had been done longer ago.

The results of the assessment of the attractiveness of tattooed women and soldiers perceptions of the attractiveness of tattoos to women (Table 5) indicate that whilst $50.1 \%$ of all respondents find tattoos on girls ugly, very significantly less do of those who are themselves tattooed. Only a very small number of soldiers felt that tattoos were attractive to women. Most $(96.2 \%)$ felt that they were either irrelevant or unattractive. A significantly higher number of men without tattoos think tattoos are unattractive to women.

\section{Discussion}

This study looked at soldiers who came into a garrison medical centre during a one month period. Although no publicity was given to the trial this did give a potential for volunteer bias in the study population. The author wished to avoid as much as possible the effects of peer group pressure on the answers given. It was felt that the method chosen was the most practical way of achieving this aim. Questionnaires given to large groups of soldiers could have both increased the size of the study and eliminated volunteer bias, but given the intimacy in which soldiers live and work such a method could undoubtedly have resulted in group answers. The medical centre reception staff who supervised the distribution and collection of the questionnaires reported an absence
Table 5

The attractiveness of tattoos; a comparison between the attitudes of those tattooed and not tattooed (with percentages in brackets).

\begin{tabular}{|c|c|c|c|}
\hline & $\begin{array}{c}\text { Tattooed } \\
\text { subject }\end{array}$ & $\begin{array}{l}\text { Not } \\
\text { tattooed } \\
\text { subject }\end{array}$ & $\begin{array}{r}\text { 을 } \\
\text { Th } \\
\text { Totati }\end{array}$ \\
\hline $\begin{array}{l}\text { Find tattoos in } \\
\text { girls attractive }\end{array}$ & $84(42.9)$ & $24(9.6)$ & 108(2造3) \\
\hline $\begin{array}{l}\text { Indifferent to } \\
\text { tattoos in girls }\end{array}$ & $57(29.1)$ & $57(22.9)$ & 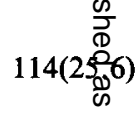 \\
\hline $\begin{array}{l}\text { Find tattoos in } \\
\text { girls ugly }\end{array}$ & $55(28.1)$ & $168(67.5)$ & $223\left(\frac{\overrightarrow{0}}{\frac{\dot{0} \vec{\omega}}{\omega}}\right)$ \\
\hline $\begin{array}{l}\text { Think tattoos are } \\
\text { attractive to girls }\end{array}$ & $13(6.6)$ & $4(1.6)$ & $17($ ( \\
\hline $\begin{array}{l}\text { Think tattoos are } \\
\text { irrelevant to girls }\end{array}$ & $151(77.0)$ & $105(42.2)$ & 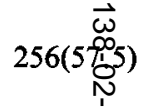 \\
\hline $\begin{array}{l}\text { Think tattoos are } \\
\text { not attractive } \\
\text { to girls }\end{array}$ & $32(16.3)$ & $140(41.8)$ & 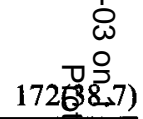 \\
\hline
\end{tabular}

Attractiveness of tattooed girls: chi-squared $=85.50$, $\mathrm{p}<0.0001$.

Attractiveness of tattoos to girls: chi-squared शु의, $\mathrm{p}<0.0001$.

of peer group pressure during the completion of forms.

The overall incidence of skin tattoos in the samgle population $(44 \%)$ was greater than that recorded in previous studies $(1,2)$. The number of soldiers in younger age group with tattoos was similar to that in the older group. Given that other studies (1) have dem $\overline{\text { p- }}$ strated that the mean age of first tattooing is 19 this nay suggest that despite a recent upsurge in stories about the health risks of tattoos as many younger soldiers becoming tattooed today as in previous years.

United Kingdom based tattooists proved to be most common performers of tattoos for the stouty population. This applied to both the older and younger age groups. A higher percentage $(49.5 \%$ as opposeç大to $22.1 \%$ ) of the older group had been tattooed abrowd. This may indicate changing attitudes and concern about hygiene standards or may simply reflect the different opportunities for travel abroad amongst today's younger soldiers.

The term UK based recognised tattooist used in questionnaire is of necessity a loose one. Other authors $(12,13)$ have discussed the present widespread flouting of the Local Government Miscellaneous Provisions Ret 1982 which is supposed to regulate tattoo artistry in fre $^{2}$ United Kingdom. In this study recognised was taken to 
mean an artist working for commercial gain.

The trend for self inflicted or homemade tattoos in the younger soldier should be a cause for concern. 'Amateur' tattoos are often less aesthetically pleasing than professionally performed ones and this gives the potential for a higher rate of requests for removal in the future. Removal of such tattoos may even produce its own particular difficulties (14). Instruments used in home tattooing are unlikely to be adequately sterilized and may be used on several different people presenting an increased risk of transmission of infection. Some authors (15) have raised the question of legislation against tattooists. The results of this survey suggest that a proportion of young soldiers have already been involved in amateur tattooing and legislation outlawing tattoo parlours may drive the practice underground with attendant health risks. Education about the risks involved may be a more satisfactory solution.

The influence of male friends on tattooing was felt to be over $50 \%$ in both the younger and older age groups. This evidence supports previous findings $(1,8)$. The influence exerted by girls was shown to be much lower $(17.5 \%)$. Any health education programme must address this strong influence of other young men on the peers.

This study confirmed previous work (16) which suggested that the numbers of tattoos which an individual has is not an important factor in assessing the attitudes of the subjects. A soldier with five or less tattoos seems to be no more or less likely to regret his tattoos than one with five or more.

The results from questioning concerning regrets about tattooing and requests for removal support the clinical impression that it is usually the older male who wishes to consider tattoo removal. The medical problems associated with tattoo removal have been reviewed elsewhere $(11,14)$ and the potential number of patients involved has implications for those plastic surgery units dealing with soldiers. Some of the men who have come to regret their tattoos may be willing to provide advice to young soldiers and may be able to make an important contribution to any health education package.

Most previous work on women and tattoos has been prisoner and psychiatric patient based rather than reflecting views of the general population. This study showed that the majority of men find tattoos in women unattractive. This evidence may be of use in influencing women not to become tattooed.

The results obtained in this study were from a single group of soldiers in a single garrison. Although the author has no reason to believe that the soldiers questioned were not typical it would be unwise to extrapolate the incidence of tattoos found for the British Army as a whole. The results do, however reflect previous work with soldiers (17).

It is to be hoped that in future the present rate of tattooing in the British Army can be reduced by the combined efforts of medical staff and unit commanders.
Preventative programmes have already been described (18) and the results of this survey suggest that the edu- $>$ cation of the young soldier about the medical risks ando lifelong nature of the tattoo is important. We must work as some authors have suggested, (19) to provide practicalo alternatives to tattooing and ensure that the soldier isco fully aware of the implications of becoming tattooed.

\section{Acknowledgements}

I would like to thank Mrs M M Sims (MOD Med Stats) for her assistance with the statistical analysis of this? study.

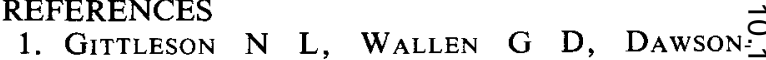
BUTTERWORTH K. The tattooed psychiatric patient $\overrightarrow{\vec{\omega}}$ Br J Psychiatry 1969; 115: 1249-1253.

2. Gittleson N L, Wallen G D. The tattooed maleg patient. BrJ Psychiatry 1973; 122: 295-300.

3. BourgeoIS M, CAMPAGNE A. Tattooing andi psychiatry. Ann Med Psychol 1971; 2: 391-413.

4. DoLL D C. Tattooing in prisons and HIV infection. Lancet 1988; 1: 8575-6.

5. IWAMURA K. Clinicopathological aspects of livero diseases associated with early history of tattooing 0 Tokai J Exp Clin Med 1988; 13: 191-218.

6. Horney D A, Gaither J M, Lauer R, Norins A $\bar{q}$, Mathur P N. Cutaneous inoculation tuberculosise secondary to jailhouse tattooing. Arch Dermago 1985; 121: 648-50.

7. Singh G, Tutakne M A, Tiwari V D, Dutta RK Inoculation leprosy developing after tattooing $\odot$ case report. Indian J Lepr 1985; 57: 887-8.

8. VELKOBORSKY J. Tattooing of male crimina Czeskoslovenskai Psychologie 1966; 10: 563-579.?

9. Lanigan S W, Sheehnan-Dare R A, Cotterillo J A. The treatment of decorative tattoos with the carbon dioxide laser. Br J Dermatol 1989; 120: 819을 25.

10. Ruiz-Esparza J, Goldman M P, Fitzpatrick R E? Tattoo removal with minimal scarring: the chemolasar technique. $J$ Dermatol Surg Oncop. 1988; 14: 1372-6.

11. GoldSTIEN N. Tattoo removal. Dermatol Clin 1987 5: $349-58$

12. Mercer N S G, Davies D M. Tattoos - marked fo life. $B r M e d J 303: 380$.

13. Hall-SMith P, BenNeTt J. Tattoos: a lasting regret Br Med J303: 397.

14. HARRISON $\mathbf{P}$ V. The surgical removal of amateug tattoos. Clin Exp Dermatol 1985; 10: 540-4.

15. EDELSTEN G W. Legislate against tattoos? Med $\Phi$ A ust 1983; 1: 11 .

16. Newman G. The implications of tattooing in pris음 oners. J Clin Psychiatry 1982; 43: 231-234.

17. WALTZ G. Tattoos speak for soldiers. $A m$ Orthopsychiatry 1984; 54: 505.

18. TAYLOR A J. Tattooing among male and female offenders of different ages in different types of ind stitutions. Genet Psychol Monogr 1970; 81: 81-119 N

19. TAYLOR A J. Criminal tattoos. International Review of Applied Psychology 1974; 23: 121-130. 